\title{
Lack of mitochondrial trifunctional protein in mice causes neonatal hypoglycemia and sudden death
}

\author{
Jamal A. Ibdah, ${ }^{1}$ Hyacinth Paul, ${ }^{1}$ Yiwen Zhao, ${ }^{1}$ Scott Binford, ${ }^{1}$ Ken Salleng, ${ }^{2}$ Mark Cline, ${ }^{2}$ \\ Dietrich Matern, ${ }^{3}$ Michael J. Bennett, ${ }^{4}$ Piero Rinaldo, ${ }^{3}$ and Arnold W. Strauss ${ }^{5}$ \\ ${ }^{1}$ Department of Internal Medicine, and \\ ${ }^{2}$ Department of Comparative Medicine, Wake Forest University School of Medicine, Winston-Salem, \\ North Carolina, USA \\ ${ }^{3}$ Department of Laboratory Medicine and Pathology, Mayo Clinic, Rochester, Minnesota, USA \\ ${ }^{4}$ Department of Pathology, University of Texas, Dallas, Texas, USA \\ ${ }^{5}$ Department of Pediatrics, Vanderbilt University School of Medicine, Nashville, Tennessee, USA
}

Address correspondence to: Jamal A. Ibdah, Division of Gastroenterology, Department of Internal Medicine, Wake Forest University School of Medicine, Winston-Salem, North Carolina 27157, USA.

Phone: (336) 716-4621; Fax: (336) 716-6376; E-mail: JIbdah@wfubmc.edu.

Received for publication February 22, 2001, and accepted in revised form May 1, 2001.

\begin{abstract}
Mitochondrial trifunctional protein (MTP) is a hetero-octamer of four $\alpha$ and four $\beta$ subunits that catalyzes the final three steps of mitochondrial long chain fatty acid $\beta$-oxidation. Human MTP deficiency causes Reye-like syndrome, cardiomyopathy, or sudden unexpected death. We used gene targeting to generate an MTP $\alpha$ subunit null allele and to produce mice that lack MTP $\alpha$ and $\beta$ subunits. The $\mathrm{Mtpa}^{-/-}$fetuses accumulate long chain fatty acid metabolites and have low birth weight compared

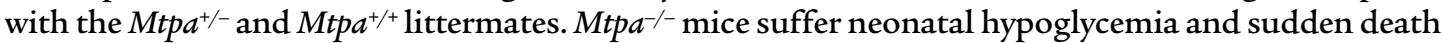
6-36 hours after birth. Analysis of the histopathological changes in the $\mathrm{Mtpa}^{-/-}$pups revealed rapid development of hepatic steatosis after birth and, later, significant necrosis and acute degeneration of the cardiac and diaphragmatic myocytes. This mouse model documents that intact mitochondrial long chain fatty acid oxidation is essential for fetal development and for survival after birth. Deficiency of MTP causes fetal growth retardation, neonatal hypoglycemia, and sudden death.
\end{abstract}

J. Clin. Invest. 107:1403-1409 (2001).

\section{Introduction}

Mitochondrial $\beta$-oxidation of fatty acids is the major source of energy for skeletal muscle and the heart, and it plays an essential role in intermediary metabolism in the liver. The $\beta$-oxidation cycle is a repetitive process of four steps. Mitochondrial trifunctional protein (MTP) is a hetero-octamer of four $\alpha$ and four $\beta$ subunits associated with the inner mitochondrial membrane that utilizes long chain fatty acids as substrate $(1,2)$. The MTP $\alpha$ subunit $\left(\mathrm{MTP}_{\alpha}\right) \mathrm{N}$-terminal domain contains the long chain 3-enoyl-CoA hydratase activity that catalyzes the second step, while long chain 3-hydroxyacylCoA dehydrogenase (LCHAD) activity resides in the Cterminal domain and catalyzes the third step. The MTP $\beta$ subunit $\left(\mathrm{MTP}_{\beta}\right)$ has the long chain 3-ketoacyl-CoA thiolase activity and catalyzes the fourth step. Human genes coding for $\mathrm{MTP}_{\alpha}(H A D H A)$ and $\mathrm{MTP}_{\beta}(H A D H B)$ are characterized and localized to chromosome 2 (3-6).

Human defects in the MTP complex are recessively inherited and can be classified into two biochemical subgroups $(2,5,7-11)$. The first has isolated LCHAD deficiency with normal or slightly reduced thiolase and hydratase activities, while the second has complete MTP deficiency with markedly reduced activity of all three enzymes. In the United States, a defect in MTP causing complete MTP deficiency or isolated LCHAD deficiency occurs about once in 38,000 pregnancies
(11). Recently, we reported HADHA mutations and phenotypes in 24 patients (11). Patients with the more common, isolated LCHAD deficiency present predominantly with a Reye-like syndrome and carry a prevalent mutation (G1528C, E474Q) on one or both HADHA alleles, whereas patients with complete MTP deficiency present predominantly with cardiomyopathy or neuromyopathy and carry mutations other than the prevalent $\mathrm{G} 1528 \mathrm{C}$ mutation. Individuals with either isolated LCHAD deficiency or complete MTP deficiency may also present with sudden, initially unexplained death in infancy $(2,4,11-14)$. Furthermore, fetal MTP defects cause a fetal-maternal interaction with the development of maternal liver disease. Many heterozygote women who carry fetuses with isolated LCHAD deficiency develop acute fatty liver of pregnancy or the HELLP (hemolysis, elevated liver enzymes, and low platelets) syndrome $(4,11,14-17)$. In addition, fetal and perinatal outcome may be affected by the fetal defects in MTP, as higher frequencies of prematurity and intrauterine growth retardation (IUGR) have been documented in these individuals (ref. 16; and J.A. Ibdah, unpublished data).

Here, we report the generation and characterization of a knockout mouse model for complete MTP deficiency with biochemical changes identical to those of human deficiency. Homozygous deficient mice suffer 


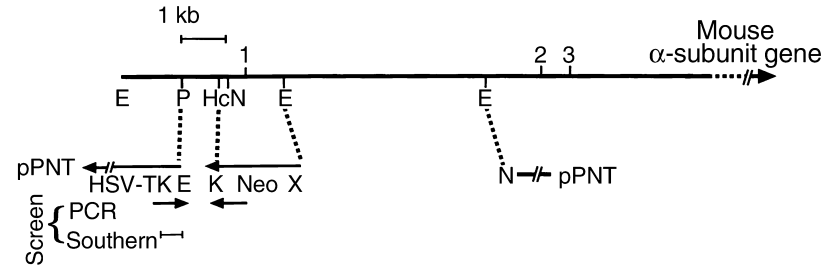

Figure 1

Targeting of the mouse Mtpa gene. A schematic diagram of MTP $\alpha$ knockout construct. Restriction enzyme sites are indicated by E, EcoRI; P, Pstl; Hc, Hincl; N, Notl; K, Kpnl; and X, Xhol. HSV-TK is the herpes simplex virus thymidine kinase cassette in the PPNT targeting vector.

intrauterine fetal growth retardation, hypoglycemia, and early neonatal death.

\section{Methods}

Generation of MTP-deficient mice. Primers from human $\alpha$-subunit cDNA were used to amplify a segment of mouse strain $129 / \mathrm{SvJ}$ heart mRNA encoding the $\alpha$ subunit. This fragment of mouse cDNA was used to initially screen a mouse heart cDNA library. A full-length cDNA for the mouse cDNA was isolated. Primers designed from the cDNA coding regions were then used to isolate a P1 mouse $129 / \mathrm{SvJ}$ genomic clone. A $15-\mathrm{kb}$ genomic fragment containing exons 1, 2, and 3 of $M t p a$ (the mouse gene homologous to human $H A D H A$ ) was subcloned and used to create a targeting construct by replacing an Mtpa 1.6-kb region containing exon 1 by a neomycin phosphotransferase gene (neo) driven by phosphoglycerate kinase (PGK) promoter. To create this construct (Figure 1), an Mtpa 900 bp fragment upstream of the $1.6 \mathrm{~kb}$ region containing exon 1 was isolated and subcloned in the EcoRI-KpnI site of a pPNT vector between the neo and herpes simplex virus thymidine kinase (HSV-TK) expression cassettes in an opposite orientation. To create the long arm of the targeting construct, an Mtpa 4.7 intronic fragment downstream of exon 1 was isolated and subcloned in the XhoI-NotI site of the PPNT vector, in an opposite orientation. RW4 embryonic stem (ES) cells from 129X1/SvJ strain (Genome Systems Inc., St. Louis, Missouri, USA) were then transfected with the replacement-targeting vector using electroporation. Positive/negative drug selection strategy was employed and 110 colonies were selected. Three colonies were identified by PCR and Southern blot analyses that successfully underwent homologous recombination and contained the neo mutation. Two hundred thirty-four C57BL/6J blastocysts were injected with the successfully targeted mycoplasma-free ES cells and implanted into pseudopregnant C57BL/6J female mice. Eighteen male chimeric offspring were mated with NIH Swiss black female mice to produce F1 progeny. The care of the animals was in accordance with Wake Forest University School of Medicine and Institutional Animal Care and Use Committee guidelines.

Genotyping of mice. To facilitate genotyping analysis of the large number of mice generated, we designed three oligonucleotide primers to distinguish the mutant allele from the wild-type allele by PCR (Figure 1). Separate PCR analyses were used to distinguish the PCR products $(\sim 950 \mathrm{bp})$ from the wild-type and mutant alleles. All PCR analyses were confirmed in duplicates. We verified the initial PCR analyses by Southern blot analysis in 12-16 mice of each genotype. For Southern blot analysis, $10 \mu \mathrm{g}$ genomic DNA was subjected to EcoRI and NotI digestion prior to transfer, then hybridized with a ${ }^{32} \mathrm{P}$-labeled probe. We used an approximately 750-bp PstI fragment from the Mtpa 5' flanking region located outside of the targeting vector (Figure 1) as a probe to screen for correctly targeted ES cell clones and subsequent mutant mice. Replacement of the Mtpa exon 1 and the flanking regions by the PGK-neo cassette deleted a NotI restriction site upstream of exon 1 (Figure 1). Consequently, this probe detected a $2.2-\mathrm{kb}$ fragment in the wild-type allele and a $4.1-\mathrm{kb}$ fragment in the mutant allele containing the PGK-neo cassette.

Northern blot analysis. Total RNA from various tissues was isolated using the guanidinium thiocyanate method (18). RNA samples were analyzed by formaldehyde gel electrophoresis and ethidium bromide staining. Northern blot analysis was performed using the mouse $\alpha$-subunit ${ }^{32} \mathrm{P}-\mathrm{cDNA}$ probe. Staining of the transferred RNA with ethidium bromide was used to ensure uniform total cellular RNA recovery and transfer.

Western blot analysis. This was performed following $10 \%$ SDS-PAGE according to Laemmli (19) with rabbit polyclonal antibodies raised against the mouse LCHAD domain of $\mathrm{MTP}_{\alpha}$, the entire mouse $\mathrm{MTP}_{\beta}$, and the entire mouse short chain 3-hydroxyacyl-CoA dehydro-

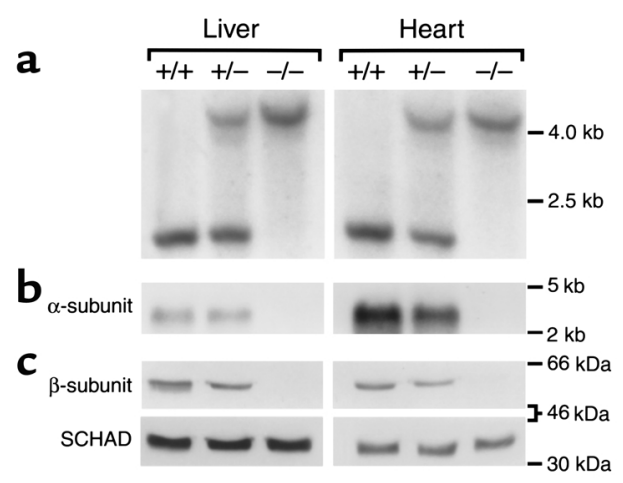

\section{Figure 2}

Molecular characterization of MTP-deficient mice. Representative Southern blot (a), Northern blot (b), and Western blot (c) analyses using DNA, total RNA, and protein isolated from liver and heart tissues from pups sacrificed at birth with different genotypes: $\mathrm{Mtpa}^{+/+}$ $(+/+), \mathrm{Mtpa}^{+/-}(+/-)$, and $\mathrm{Mtpa}^{-/-}(-/-)$. Southern blot analysis was performed using EcoRI and Notl digestion. Mtpa ${ }^{+/+}$mice had one band corresponding to the wild-type 2.2-kb fragment, $\mathrm{Mtpa}^{+/-}$mice had two bands corresponding to the wild-type 2.2-kb fragment and a mutant 4.1-kb fragment containing the neo cassette (see Figure 1), and $\mathrm{Mtpa}^{-1-}$ mice had the mutant 4.1-kb band. An $\alpha$-subunit cDNA probe was used in the Northern blot analysis, and antibodies raised against $\mathrm{MTP}_{\beta}$ or $\mathrm{SCHAD}$ were used in the Western blot analyses. 
Table 1

Serum laboratory tests ${ }^{\mathrm{A}}$ and genotypes in MTP knockout mice

\begin{tabular}{lcccc}
\hline & $+/+$ & $+/-$ & $-/-($ Asymptomatic) & $-1-$ (Symptomatic $^{\mathrm{B}}$ \\
& $(n=25)$ & $(n=30)$ & $(n=16)$ & $(n=13)$ \\
Glucose $(\mathrm{mg} / \mathrm{dl})$ & $44 \pm 11.4$ & $36.8 \pm 6.7$ & $16.5 \pm 4.3$ & $<10$ \\
ALT $(\mathrm{U} / \mathrm{l})$ & $50.4 \pm 3.4$ & $53.4 \pm 6.2$ & $61.5 \pm 5.1$ & $104.6 \pm 20.3$ \\
Bilirubin $(\mathrm{mg} / \mathrm{dl})$ & $0.44 \pm 0.09$ & $0.44 \pm 0.05$ & $0.55 \pm 0.1$ & $1.9 \pm 0.58$ \\
GGT $(\mathrm{U} / \mathrm{l})$ & $14 \pm 2.6$ & $14.3 \pm 2.1$ & $14.7 \pm 1.5$ & $25 \pm 2.6$ \\
Urea $(\mathrm{mg} / \mathrm{dl})$ & $32.2 \pm 3.7$ & $35.6 \pm 2.9$ & $54.2 \pm 14.4$ & $97 \pm 31.2$
\end{tabular}

${ }^{A}$ Mean \pm SD. ${ }^{B}$ Asymptomatic, sacrificed before showing symptoms; symptomatic, sacrificed after appearing weak, dehydrated, and separated from the litter.

genase (SCHAD) expressed in bacteria. For this, the corresponding cDNA was placed into the NdeI and SalI sites of the bacterial expression plasmid, pet21a (Novagen, Madison, Wisconsin, USA). After transformation into Escherichia coli and induction with isopropyl $\beta$-D-thiogalactoside for 4 hours, bacteria were lysed by sonication and centrifuged at $5,000 \mathrm{~g}$. The supernatant was analyzed by SDS gel electrophoresis. The corresponding band was excised form the gel and injected into rabbits as the antigen. Antisera were diluted 1:2000.

Biochemical analyses. All blood samples were obtained at the time of sacrifice by cardiac puncture. Sera were analyzed using an automated analyzer (Technicon CHEM I; Bayer Corp., Tarrytown, New York, USA) for measurement of glucose, alanine aminotransferase (ALT), bilirubin, gamma glutamyl transferase (GGT), and urea levels. Serum and tissue FFAs, serum acyl carnitines, and urine organic acids were analyzed by using gas chromatography-mass spectrometry as previously described (20). The activities of LCHAD and long chain 3-ketoacyl-CoA thiolase were measured in crude extracts of liver, skeletal muscle, or heart tissues, as previously described (21). Because the active sites of these two enzymes are in the $\alpha$ and $\beta$ subunits of the MTP, respectively, a deficiency of both activities is always associated with a lack of activity of long chain 2,3 enoyl-CoA hydratase whose active site is in the $\alpha$ subunit.

Histopathological analysis. Tissues were collected and fixed in $4 \%$ paraformaldehyde for histology or $2.5 \%$ glu- taraldehyde for electron microscopy. Tissues for routine histology were trimmed to less than $3 \mathrm{~mm}$ in thickness, embedded in paraffin, sectioned at $4 \mu \mathrm{m}$, and stained with hematoxylin and eosin. Tissues used to detect the presence of fat were quick-frozen, cryostatically sectioned at $4 \mu \mathrm{m}$, and stained using Oil Red $\mathrm{O}$ (Hartman-Leddon Co., Philadelphia, Pennsylvania, USA). Tissues used for electron microscopy were postfixed in osmium tetroxide, embedded in Spurr's resin, sectioned at $90 \mathrm{~nm}$, and stained with uranyl acetate/lead citrate. All sections were reviewed by a board-certified veterinary pathologist who was blinded to the genotype of the animals. Standard histopathologic criteria were used for the assessment of tissue viability, necrosis, and degenerative changes at the light-microscopic and electron-microscopic levels.

\section{Results}

Generation and molecular characterization of MTP-deficient mice. A targeting vector was used to replace Mtpa exon 1 , a flanking $5^{\prime}$ upstream region, and an intron 1 region by a PGK-neomycin-resistance cassette (neo) using homologous recombination in 129X1/SvJ ES cells (Figure 1). Heterozygous F1 mice were then intercrossed to produce the three genotypes: wild-type $\left(\mathrm{Mtpa}^{+/+}\right)$, heterozygotes $\left(\mathrm{Mtpa}^{+-}\right)$, and homozygotes $\left(\mathrm{Mtpa}^{-/-}\right)$. All mice analyzed in this study were F2 and F3 generations.

Figure 2 shows a representative Southern blot (Figure 2a) using EcoRI and NotI digestion and the probe illustrated in Figure 1, a Northern blot using $\alpha$ subunit cDNA probe (Figure $2 b$ ), and a Western blot with $\beta$ subunit antibodies as a surrogate for the MTP complex (Figure 2c) with DNA, RNA, and protein isolated from the livers and hearts of pups with different genotypes sacrificed at birth. $\mathrm{Mtpa}^{-/-}$mice have no detectable $\mathrm{MTP}_{\alpha}$ mRNA, whereas $\mathrm{Mtpa}^{+/-}$mice have intermediate levels. High expression is obvious in the cardiac muscle

Table 2

Representative mean values of biochemical metabolites in $\mathrm{Mtpa}^{+/+}$and symptomatic $\mathrm{Mtpa}^{-/-}$mice

\begin{tabular}{|c|c|c|c|c|c|c|c|c|c|c|}
\hline \multirow[t]{2}{*}{ Fatty acid } & \multicolumn{2}{|c|}{$\begin{array}{l}\text { Serum total fatty acids } \\
(\mu \mathrm{mol} / \mathrm{l})\end{array}$} & \multicolumn{2}{|c|}{$\begin{array}{c}\text { Serum acylcarnitines } \\
(\mu \mathrm{mol} / \mathrm{l})\end{array}$} & \multicolumn{2}{|c|}{$\begin{array}{l}\text { Serum 3-hydroxy acylcarnitine } \\
(\mu \mathrm{mol} / \mathrm{l})\end{array}$} & \multicolumn{2}{|c|}{$\begin{array}{l}\text { Urine dicarboxylic acids } \\
\text { (mmol/mol creatinine) }\end{array}$} & \multicolumn{2}{|c|}{$\begin{array}{l}\text { Liver fatty acids } \\
(\mu \mathrm{mol} / \mathrm{g} \text { protein })\end{array}$} \\
\hline & $+/+$ & $-/-$ & $+/+$ & $-/-$ & $+/+$ & $-/-$ & $+/+$ & $-/-$ & $+/+$ & $-/-$ \\
\hline C8 & 19.7 & 15.1 & 0.26 & 0.23 & - & - & 102.0 & $887.4^{\mathrm{A}}$ & 0.088 & 0.291 \\
\hline C10:1 & 1.3 & 1.1 & 0.1 & 0.11 & - & - & 2.7 & $172.3^{\mathrm{A}}$ & 0.000 & 0.000 \\
\hline C10 & 5 & 9.0 & 0.22 & 0.31 & - & - & 10.6 & $1790.1^{\mathrm{A}}$ & 0.007 & 0.013 \\
\hline C12:1 & 0.8 & 1.3 & 0.12 & 0.12 & 0.84 & 0.71 & - & - & 0.000 & 0.000 \\
\hline C12 & 10.1 & 26.7 & 0.38 & 0.58 & 0.15 & 0.22 & - & - & 0.018 & $0.095^{A}$ \\
\hline C14:1 & 1.5 & $6.6^{\mathrm{A}}$ & 0.21 & 0.36 & 0.34 & 0.30 & - & - & 0.002 & $0.017^{A}$ \\
\hline C14 & 16.8 & $59.1^{\mathrm{A}}$ & 0.33 & $1.42^{\mathrm{A}}$ & 0.29 & 0.42 & - & - & 0.058 & $0.195^{A}$ \\
\hline C16:1 & 14.4 & $96.4^{\mathrm{A}}$ & 0.24 & $0.9^{\mathrm{A}}$ & 0.07 & $0.37^{A}$ & - & - & 0.336 & $1.171^{\mathrm{A}}$ \\
\hline C16 & 122.7 & $412.7^{A}$ & 0.54 & $3.34^{\mathrm{A}}$ & 0.18 & $0.76^{\mathrm{A}}$ & - & - & 2.014 & 4.361 \\
\hline C18:2 & 51.5 & $162.6^{\mathrm{A}}$ & 0.14 & $0.34^{\mathrm{A}}$ & - & - & - & - & 2.372 & $4.054^{A}$ \\
\hline C18:1 & 83.5 & $429.3^{\mathrm{A}}$ & 0.07 & $0.5^{\mathrm{A}}$ & - & - & - & - & 3.354 & $6.836^{A}$ \\
\hline C18 & 80 & 65.7 & 0.08 & 0.19 & - & - & - & - & 0.594 & 1.069 \\
\hline
\end{tabular}

${ }^{A} P<0.05\left(n=5\right.$ and 8 for $\mathrm{Mtpa}^{+/+}$and $\mathrm{Mtpa}^{-/-}$mice, respectively). 
Table 3

Heart enzymatic activities ${ }^{\mathrm{A}}$ in MTP knockout mice

\begin{tabular}{lcccc}
\hline Genotype & LCHAD & \multicolumn{1}{c}{ SCHAD } & $\begin{array}{c}\text { Long chain } \\
\text { 3-ketothiolase }\end{array}$ & $\begin{array}{c}\text { Short chain } \\
\text { 3-ketothiolase }\end{array}$ \\
& & & & \\
$+/+$ & $317.0 \pm 14.7$ & $730.3 \pm 25.8$ & $124.5 \pm 15.3$ & $36.1 \pm 36.2$ \\
$+/-$ & $195.4 \pm 95.5$ & $656.4 \pm 202.9$ & $75.1 \pm 37.3^{\mathrm{C}}$ & $48.9 \pm 25.1$ \\
$-/-$ & $96.5 \pm 19.4^{\mathrm{B}}$ & $659.3 \pm 91.3$ & $16.2 \pm 6.8^{\mathrm{B}}$ & $45.4 \pm 23.3$
\end{tabular}

${ }^{A}$ Mean $\pm \mathrm{SD}(\mathrm{nmol} / \mathrm{min} / \mathrm{mg}$ protein $), n=5$ for each genotype. ${ }^{\mathrm{B}} P<0.001$ compared with $\mathrm{Mtpa}^{+/+}$and $P<0.05$ compared with $\mathrm{Mtpa}^{+/-} .{ }^{C} P<0.01$ compared with $\mathrm{Mtpa}^{+/+}$

at birth in the $\mathrm{Mtpa}^{+/+}$mice (Figure 2b). The MTP complex is absent in the $M t p a^{-/-}$mice and has intermediate expression in the $M \mathrm{tpa}^{+/-}$mice for both $\alpha$ and $\beta$ subunits (Figure 2c, data for the $\alpha$ subunit not shown). As a control, we used antibodies raised against the homologous SCHAD to determine SCHAD protein expression in pups with different genotypes. The results in Figure 2c show equal expression of SCHAD at birth in all three genotypes without compensatory increase in the MTPdeficient mice. Thus, $M \mathrm{tpa}^{-/-}$mice lack MTP complex as determined by Western blot analysis and hence lack the activity of all MTP enzymes. The above analyses were confirmed in 12-16 pups of each genotype.

Sudden neonatal death of MTP-deficient mice. All $\mathrm{Mtpa}^{-/}$ mice died within 6-36 hours after birth, most within 12-24 hours. Thirty-eight litters (345 pups) of crosses between $\mathrm{Mtpa}^{+/-}$parents and 27 control litters (244 pups) from $\mathrm{Mtpa}^{+/+}$mice were observed closely for 48 hours after birth (at least four times a day by two different observers). Eighty-one pups died in the litters of the crosses between $M t p a^{+/-}$mice. Of these, 78 were $\mathrm{Mtpa}^{-/-}$, two were $\mathrm{Mtpa}^{+/-}$, and one was $\mathrm{Mtpa}^{+/+}(100 \%$, $1.2 \%$, and $1.2 \%$ of the $\mathrm{Mtpa}^{-/-}, \mathrm{Mtpa}^{+/-}$, and $\mathrm{Mtpa}^{+/+}$pups, respectively). By comparison, four pups (1.6\%) died in the litters from $M t p a^{+/+}$mice. Most of the $\mathrm{Mtpa}^{-/-}$pups' deaths were sudden. However, some $\mathrm{Mtpa}^{-/-}$pups became symptomatic (weak with lack of suckling activity, separated from the litter) for a brief period of time (1-3 hours) prior to death.

We measured serum levels of glucose, bilirubin, parenchymal and cholestatic hepatic enzyme markers (ALT and GGT, respectively), and serum urea in pups of different genotypes sacrificed within 36 hours after birth, including $\mathrm{Mtpa}^{-/-}$pups that were symptomatic (Table 1 ). The results show significant differences in the glucose levels between the $\mathrm{Mtpa}^{-/-}$ pups and $\mathrm{Mtpa}^{+/+}$or $\mathrm{Mtpa}^{+/-}$ pups $(P<0.001$ and $P<0.002$, respectively), but the difference between the heterozygotes and wild-type was not significant $(P=0.212)$. There were mild but significant elevations of ALT in the Mtpa-/pups compared to the $\mathrm{Mtpa}^{+/+}$

\section{Table 4}

or $M t p a^{+/-}$pups $(P<0.05)$, with more significant elevations of ALT, GGT, and bilirubin in the symptomatic $\mathrm{Mtpa}^{-/-}$pups. The urea level was also significantly elevated in the $\mathrm{Mtpa}^{-/-}$pups, with a normal creatinine level, suggesting that $\mathrm{Mtpa}^{-/-}$ pups were dehydrated.

We performed frequent intraperitoneal glucose injections starting at birth in seven litters of crosses between $\mathrm{Mtpa}^{+/-}$mice $(50 \mu \mathrm{l} 5 \%$ dextrose, every 4 hours for 5 days). Litters were not separated from dams. Despite treatment, $16 \mathrm{Mtpa}^{-/-}$pups died within 96 hours after birth: 13 within 36 hours, two within 48-72 hours, and one at 96 hours. None of the remaining 46 surviving pups was homozygous. Thus, treatment with glucose prolonged survival in some affected mice, but did not prevent death.

Biochemical analysis. Characterization of the biochemical phenotype was based on the analysis of coded specimens of serum, liver, and urine of five $\mathrm{Mtpa}^{+/+}$, five $\mathrm{Mtpa}^{+/-}$, five asymptomatic $\mathrm{Mtpa}^{-/-}$, and eight symptomatic $M t p a^{-/-}$mice sacrificed within 24 hours of birth. In serum, quantitative analyses were performed of the following metabolites: carnitine, C2-C18 acylcarnitines and C12-C16 3-hydroxy acylcarnitines, C8-C18 total fatty acids, and C6-C16 free 3-hydroxy fatty acids. C6-C10 dicarboxylic acids and C6-C14 3-hydroxy dicarboxylic acids were also measured in urine. C8-C18 fatty acids and carnitine were analyzed in liver homogenates. Differences between $M t p a^{+/+}$and $M t p a^{+/-}$mice were not statistically significant $(P>0.1)$. However, the $\mathrm{Mtpa}^{-/-}$ mice clearly had abnormal biochemical features identical to those observed in human cases with MTP deficiency (22) including elevated C8-C14 urine dicarboxylic acids and C14-C18 serum acyl carnitines and fatty acids $(P<0.05)$. These biochemical changes in the $\mathrm{Mtpa}^{-/-}$mice were most significant in the symptomatic mice (Table 2). Serum free carnitine levels were significantly reduced in the asymptomatic and symptomatic $M t p a^{-/-}$mice $(P<0.01)$ compared with the $\mathrm{Mtpa}^{+/+}$and $\mathrm{Mtpa}^{+/-}$mice. Serum free carnitine levels were $19.2 \pm 14.2,18 \pm 9,57.7 \pm 20$, and $46.4 \pm 22.8 \mu \mathrm{mol} / \mathrm{l}$ for asymptomatic $\mathrm{Mtpa}^{-/-}$, symptomatic $\mathrm{Mtpa}^{-/-}, \mathrm{Mtpa}^{+/+}$, and $\mathrm{Mtpa}^{+/-}$mice, respectively.

Comparison of histological changes among various genotypes in MTP knockout mice

\begin{tabular}{|c|c|c|c|c|c|c|c|c|c|}
\hline \multirow[t]{2}{*}{ Genotype } & \multicolumn{3}{|c|}{ Hepatic lipidosis } & \multicolumn{3}{|c|}{$\begin{array}{l}\text { Cardiomyocyte } \\
\text { degeneration }\end{array}$} & \multicolumn{3}{|c|}{$\begin{array}{c}\text { Diaphragmatic myocyte } \\
\text { degeneration }\end{array}$} \\
\hline & $\%$ & $\begin{array}{l}\text { mean } \\
\text { score }^{A}\end{array}$ & index & $\%$ & $\begin{array}{l}\text { mean } \\
\text { score }^{A}\end{array}$ & index & $\%$ & $\begin{array}{l}\text { mean } \\
\text { score }^{A}\end{array}$ & index \\
\hline$+/+(n=17)$ & 28 & 1 & $28 \pm 46$ & 17 & 1 & $17 \pm 39$ & 0 & 0 & 0 \\
\hline$+/-(n=29)$ & 35 & 1.1 & $39 \pm 56$ & 14 & 1 & $14 \pm 35$ & 0 & 0 & 0 \\
\hline $\begin{array}{l}-/-(n=14) \\
\text { Sac }(n=5) \\
\text { Sympt }(n=4)\end{array}$ & $\begin{array}{c}60 \\
100\end{array}$ & $\begin{array}{c}2 \\
1.75\end{array}$ & $\begin{array}{l}120 \pm 110^{B} \\
175 \pm 43^{B}\end{array}$ & $\begin{array}{c}40 \\
100\end{array}$ & $\begin{array}{l}1 \\
2\end{array}$ & $\begin{array}{r}40 \pm 54 \\
200 \pm 0^{C}\end{array}$ & $\begin{array}{l}0 \\
0\end{array}$ & $\begin{array}{l}0 \\
0\end{array}$ & $\begin{array}{l}0 \\
0\end{array}$ \\
\hline Dead $(n=5)$ & 100 & 1.2 & $120 \pm 44^{B}$ & 100 & 1.4 & $140 \pm 54^{c}$ & 100 & 1.41 & $140 \pm 54$ \\
\hline
\end{tabular}

A Histological score: $0=$ no lesion, $1=$ minimal to mild, $2=$ moderate to severe. ${ }^{\mathrm{B}} P<0.05$ and $\mathrm{C} P<0.001 \mathrm{com}$ pared with $\mathrm{Mtpa}^{+/+}$and $\mathrm{Mtpa}^{+/-}$. Index, percent $\times$score. Sac, sacrificed at birth; Sympt, sacrificed after appearing weak, dehydrated, and separated from the litter. 

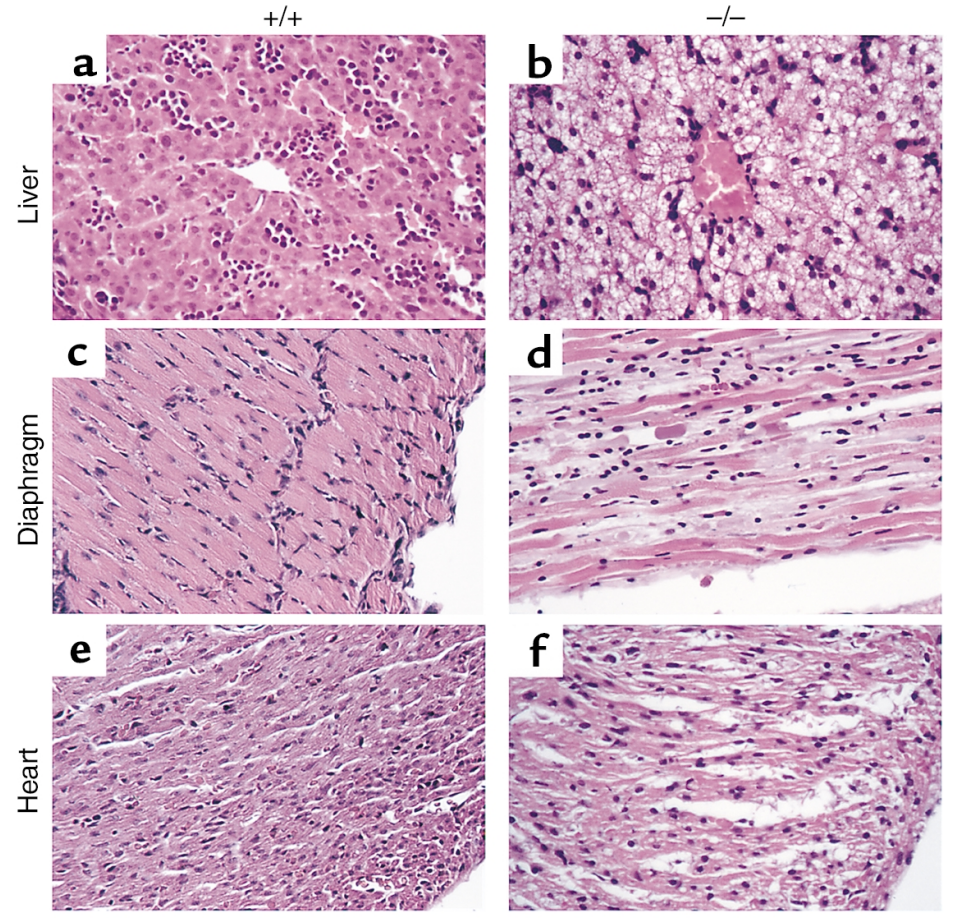

\section{Figure 3}

Histopathological analyses of MTP-deficient mice. Representative sections from liver, diaphragm, and heart obtained from approximately 12-hour-old $\mathrm{Mtpa}^{+/+}$(a, c, and e, respectively) and dead $\mathrm{Mtpa}^{-/-}$mice (b, d, and f, respectively) stained with hematoxylin and eosin $(\times 40)$.

Enzymatic measurements of LCHAD and long chain thiolase activities in samples of liver, heart, and muscle homogenates of five $\mathrm{Mtpa}^{+/+}$, five $\mathrm{Mtpa}^{+/-}$, and five $\mathrm{Mtpa}^{-/}$ mice sacrificed at birth revealed marked reductions similar to those reported in human MTP deficiency $(2,5,6$, $9,11,21)$. Table 3 shows the activities of cardiac LCHAD and long chain 3-ketothiolase in comparison with activities of SCHAD and short chain 3-ketothiolase. Similar results were obtained from enzymatic measurements in the other tissues (data not shown).

Histopathological analysis. We studied the histopathological changes in 60 pups from seven litters of crosses between $\mathrm{Mtpa}^{+/-}$mice sacrificed at 0, 6, 12, and 24 hours after birth. In these litters, five pups died within 6-24 hours after birth, and another four pups became symptomatic and were sacrificed. All symptomatic and dead pups were $\mathrm{Mtpa}^{-/-}$by PCR and Southern blot analysis. Gross findings included diffuse hepatic enlargement and yellow hepatic discoloration in the symptomatic and dead MTP-deficient pups. No gross abnormalities were noted in other organs. Table 4 shows the frequency and severity of the histological lesions in pups with different genotypes. Representative histological changes in the dead $\mathrm{Mtpa}^{-/-}$pups compared with $\mathrm{Mtpa}^{+/+}$pups are illustrated in Figure 3. All dead and symptomatic $\mathrm{Mtpa}^{-/-}$pups and three-fifths of asymptomatic $\mathrm{Mtpa}^{-/-}$ pups showed moderate to severe hepatic lipidosis (Figure $3 b$ ). Oil Red O-stain on frozen sections showed micro- and macrovesicular fatty infiltration pattern (data not shown). All dead $\mathrm{Mtpa}^{-/-}$pups had moderate to severe necrosis and vacuolation, with acute degenerative changes of the cardiac and diaphragmatic myocytes (Figure 3, $\mathrm{d}$ and f). All symptomatic $\mathrm{Mtpa}^{-/-}$pups had moderate to severe cardiomyocyte degeneration and necrosis, but none had acute degenerative changes in the diaphragm. All $M t_{p a-r}$ pups sacrificed immediately at birth showed no histological lesions. Thus, Mtpa-/- pups develop hepatic lipidosis very rapidly after birth and, later, cardiac and diaphragmatic lesions.

Three dead and three symptomatic pups were also examined for ultrastructural changes by electron microscopy. Figure 4 shows the ultrastructural changes in the hepatocytes of a symptomatic pup with significant fatty vacuolation and swollen, distorted mitochondria.

Gestational complications. We investigated the possibility of intrauterine fetal death of the $\mathrm{Mtpa}^{-/}$fetuses by performing cesarean section and examining the fetuses at 9, 12, 15, and 19 days post coitus $(\mathrm{dpc})$ in 27 litters of crosses between $\mathrm{Mtpa}^{+/-}$mice and 11 litters from $\mathrm{Mtpa}^{+/+}$ mice for comparison. There was no statistically significant difference in the litter size $(9.1 \pm 3.1$ and $9.7 \pm 2.3$, respectively) or genotype ratios $\left(\sim 1: 2: 1, \mathrm{Mtpa}^{+/ /}: \mathrm{Mtpa}^{+/-}: \mathrm{Mtpa}^{-/-}\right.$, respectively) at different embryonic stages. Similar results were obtained by sacrificing 28 litters of crosses between $\mathrm{Mtpa}^{+/-}$mice and 27 litters from $\mathrm{Mtpa}^{+/+}$mice for comparison. Thus, MTP-deficient mice do not suffer intrauterine fetal death to a significant extent.

However, $\mathrm{Mtpa}^{-/-}$fetuses suffer significant IUGR. We measured birth weights in 28 litters of crosses between $\mathrm{Mtpa}^{+/-}$mice $\left(67 \mathrm{Mtpa}^{+/+}, 132 \mathrm{Mtpa}^{+/-}\right.$, and 70

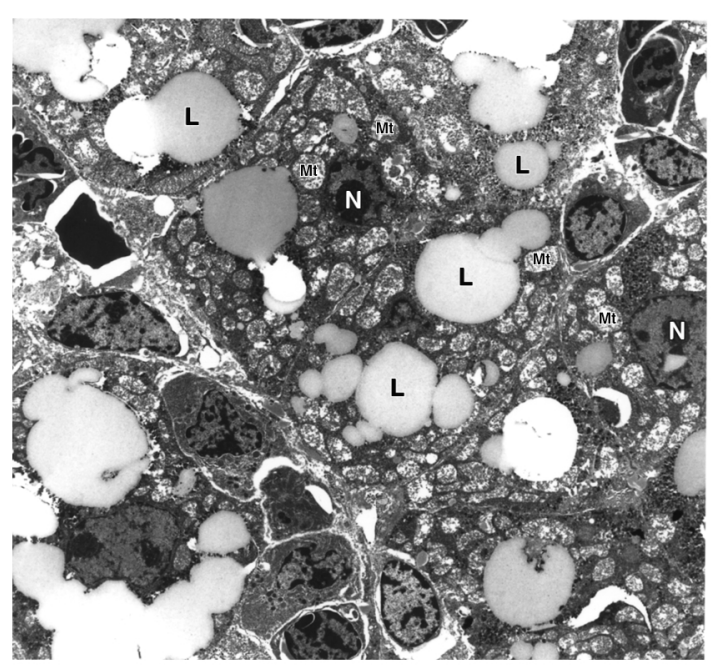

Figure 4

Hepatic ultrastructural changes in MTP-deficient mice. Representative electron microscopy of a liver section from a symptomatic $\mathrm{Mtpa}^{-1-}$ mouse 12 hours after birth showing extensive lipidosis, swelling, and distortion of mitochondria. L, lipid; Mt, mitochondria; N, nucleus. 


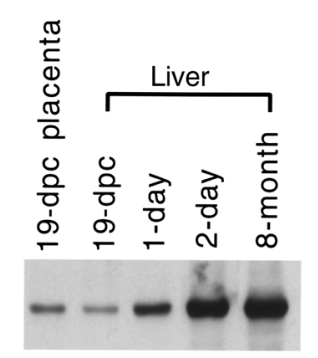

\section{Figure 5}

Developmental stage-specific expression of MTP. Representative Western blot analyses using protein isolated from $19-\mathrm{dpc}$ fetal $\mathrm{Mtpa}^{+/+}$placentae and livers from 19-dpc $\mathrm{Mtpa}^{+/+}$fetus, 1-day, 2-day, and 8-month-old $\mathrm{Mtpa}^{+/+}$mice. Antibodies raised against $\mathrm{MTP}_{\beta}$ were used in the Western blot analyses.

$M t p a^{-/-}$pups) sacrificed at birth. The mean birth weight values ( $\pm \mathrm{SD})$ for $\mathrm{Mtpa}^{+/+}, \mathrm{Mtpa}^{+/-}$, and $\mathrm{Mtpa}^{-/-}$ pups were $1.69 \pm 0.2,1.64 \pm 0.26$, and $1.42 \pm 0.16$, respectively. The low birth weight of the $\mathrm{Mtpa}^{-/-}$pups was statistically significant $(P<0.001)$ when compared with the $\mathrm{Mtpa}^{+/+}$or $M t p a^{+/-}$pups. The difference in birth weight between $M t p \mathrm{a}^{+/+}$and $M t p \mathrm{a}^{+/-}$pups was not statistically significant $(P=0.169)$. Our analysis of birth weights in the $19 \mathrm{dpc}$ fetuses confirms this observation (data not shown).

We evaluated the possibility that maternal complications or placental abnormalities cause the IUGR. Gross clinical evaluation of the pregnant $\mathrm{Mtpa}^{+/-}$dams mated with $M t p a^{+/-}$males and histopathological evaluation of the liver, heart, and muscle at different stages during pregnancy $(9,12,15$, and $19 \mathrm{dpc}, n=5,5,5$, and 12 , respectively) revealed no abnormalities. Similarly, histopathological examination of the placentae with different fetal genotypes did not reveal any abnormalities ( $n=12$ of each fetal genotype). Maternal laboratory data including liver function tests and glucose levels were not statistically significant at $P \leq 0.05$ when compared with $\mathrm{Mtpa}^{+/+}$pregnant dams carrying $\mathrm{Mtpa}^{+/+}$

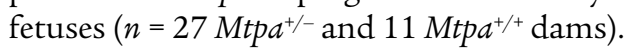

We measured serum acylcarnitines and total fatty acids in $19 \mathrm{dpc}$ fetuses in eight litters of crosses between $\mathrm{Mtpa}^{+/-}$mice (19 $\mathrm{Mtpa}^{-/-}, 31 \mathrm{Mtpa}^{+/-}$, and 15 $\mathrm{Mtpa}^{+/+}$fetuses). Mtpa-/- fetuses had significantly higher levels of long chain acylcarnitines (Table 5) and long chain fatty acids (data not shown) with particular elevations of unsaturated species (C16:1, C18:1, C18:2). These results document that MTP-deficient fetuses accumulate long chain fatty acids and metabolites secondary to impaired utilization of long chain fatty acids in the $M t_{p a /-}$ fetus and/or placenta.
Developmental stage-specific MTP expression. We determined MTP $\alpha$ and $\beta$ subunit expression in $\mathrm{Mtpa}^{+/+}$ fetuses (livers and whole homogenized mice), in placenta at 9, 15, and $19 \mathrm{dpc}$, and in livers of $\mathrm{Mtpa}^{+/+}$mice at birth, and at 1 day, 2 days, 1 week, 2 weeks, 3 weeks, 2 months, 4 months, 8 months, and 16 months of age. We detected low but significant fetal and placental expression in pregnancy starting at $9 \mathrm{dpc}$. A striking increase in neonatal hepatic MTP expression occurs after birth, reaching levels at 48 hours close to those observed in adult mice. Figure 5 shows representative Western blot analyses using antibodies raised against $\mathrm{MTP}_{\beta}$ in a $19 \mathrm{dpc} \mathrm{Mtpa}^{+/+}$placenta, and in livers from 19-dpc Mtpa $\mathrm{Tl}^{++}$fetus, 1-day, 2-day, and 8-month-old $M t p a^{+/+}$mice. These results were confirmed in three different animals of each developmental stage.

\section{Discussion}

Our results demonstrate that the MTP-deficient knockout mouse is a valid model for human MTP deficiency and that it has important implications for human disease. We have proven that intact mitochondrial long chain fatty acid oxidation is essential for fetal development and for survival after birth. Defective MTP in mice causes IUGR, neonatal hypoglycemia, and sudden neonatal death. All are serious and common human disorders.

Human studies (ref. 16; and J.A. Ibdah, unpublished data) document IUGR in fetuses with mitochondrial MTP enzymatic defects. Because most of the reported human cases were isolated LCHAD deficiency with associated maternal complications, it is difficult to determine whether the observed IUGR is secondary to fetal or maternal factors. Our current study in mice demonstrates that fetal MTP deficiency causes IUGR without associated maternal complications. Our data document an early placental and fetal expression of MTP in mice (Figure 5) suggesting a reliance of the placenta and/or the fetus on long chain fatty acid oxidation as a source of energy. This is consistent with our observation of accumulation of long chain FFAs and acylcarnitines in the $\mathrm{Mtpa}^{-/-}$fetuses (Table 5). Thus, intact mitochondrial long chain fatty acid oxidation is important for fetal development, and its impairment causes restriction of fetal growth.

The lack of the maternal phenotype in the MTP-deficient mouse model is consistent with our earlier observation in families with MTP mutations. Human maternal complications developed only in association with isolated fetal LCHAD deficiency, presumably secondary to accumulation of hepatotoxic fatty acid metabo-

Table 5

Representative mean values of serum acylcarnitines $(\mu \mathrm{mol} / \mathrm{l})$ in $19-\mathrm{dpc}$ fetuses

\begin{tabular}{|c|c|c|c|c|c|c|c|c|c|}
\hline Genotype & C10:1 & $\mathrm{C} 10$ & C12:1 & C12 & C16:1 & $\mathrm{C} 16$ & C18:2 & C18:1 & C18 \\
\hline $\begin{array}{l}+/+(n=15) \\
-/-(n=19)\end{array}$ & $\begin{array}{l}0.03 \\
0.03\end{array}$ & $\begin{array}{l}0.08 \\
0.09\end{array}$ & $\begin{array}{l}0.02 \\
0.03\end{array}$ & $\begin{array}{l}0.08 \\
0.15\end{array}$ & $\begin{array}{c}0.15 \\
1.24^{\mathrm{A}}\end{array}$ & $\begin{array}{c}0.45 \\
1.34^{\mathrm{B}}\end{array}$ & $\begin{array}{l}0.09 \\
0.7^{\mathrm{A}}\end{array}$ & $\begin{array}{c}0.24 \\
2.08^{\mathrm{A}}\end{array}$ & $\begin{array}{c}0.29 \\
0.95^{\mathrm{B}}\end{array}$ \\
\hline
\end{tabular}

$\mathrm{A} P<0.001$ and ${ }^{\mathrm{B}} \mathrm{P}<0.01$, when compared with $\mathrm{Mtpa}^{+/+}$. 
lites in the maternal circulation (11). However, it should be noted that the presence of multiple fetal genotypes in these multiparous mice may have obscured the development of the maternal phenotype. MTP deficiency in mice causes the severe phenotype of early sudden death. Sudden death in the MTP-deficient mice occurs shortly after birth; this coincides with the neonatal metabolic switch in nutritional fuel from the maternal glucose to breast milk, which is high in fat. Our expression studies (Figure 5) reveal a major increase in the MTP expression within 48 hours after birth. Thus, there is high demand for long chain fatty acid $\beta$-oxidation after birth that is essential for survival consistent with reliance upon maternal milk with high fat content as the nutritional energy source. The high expression of the MTP in the neonatal heart (Figure 2) suggests an early reliance of the heart compared with other tissues on mitochondrial $\beta$-oxidation as a source of energy. Hence, the neonatal heart is probably more susceptible than other tissues to the toxic effect of long chain FFAs and acylcarnitines. Our biochemical and histopathological analyses in the $\mathrm{Mtpa}^{-/-}$mice after birth offer insight into the likely mechanism of sudden death. The histological analyses suggest that the underlying etiology for sudden death is the cardiac and diaphragmatic lesions (Figure 3, $\mathrm{d}$ and $\mathrm{f}$ ). We suggest that the cardiac lesions may have caused cardiac arrhythmias, as found in newborns with documented long chain fatty acid oxidation disorders (23). We also suggest that the diaphragmatic lesions may have caused dysfunction of the diaphragm and subsequent respiratory insufficiency.

The phenotypes in the $\mathrm{Mtpa}^{-/-}$mice are strikingly severe compared with those observed in mice deficient in long chain acyl-CoA dehydrogenase (LCAD) (24). In humans, LCAD apparently has a limited role in mitochondrial long chain fatty acid oxidation, and to date, there are no reports of its deficiency. Significant fetal loss was reported in $L C A D^{-/-}$mice, but those achieving birth appeared normal under nonfasting conditions, although about 5\% died suddenly 4-14 weeks after birth. Thus, both $\mathrm{Mtpa}^{-/-}$and $L C A D^{-/-}$ mouse models suggest an important role for long chain fatty acid oxidation in fetal development. However, our mouse model proves that intact MTP, and, hence, intact long chain fatty acid oxidation, is essential for survival after birth.

In summary, the generation of this MTP-deficient mouse model has documented a pivotal role of long chain fatty acid $\beta$-oxidation in fetal development and has proven that intact long chain fatty acid oxidation is essential for survival. Mitochondrial long chain fatty acid oxidation disorders should be considered a significant cause for IUGR, neonatal hypoglycemia, and sudden death.

\section{Acknowledgments}

This study was supported by NIH grants DK-02574 (J.A. Ibdah) and AM-20407 (A.W. Strauss). Special thanks go to Hermina Borgerink for her expert assis- tance in the histopathological analysis. We also thank Laurie O'Brien and Beverly Gibson for their extensive efforts in preparing the antibodies to SCHAD and MTP subunits, and Harold Sims for his expert advice in mouse ES cell culture.

1. Uchida, Y., Izai, K., Orii, T., and Hashimoto, T. 1992. Novel fatty acid $\beta$ oxidation enzymes in rat liver mitochondria. II. Purification and properties of enoyl-coenzyme A (CoA) hydratase/3-hydroxyacyl-CoA dehydrogenase/3-ketoacyl-CoA thiolase trifunctional protein. J. Biol. Chem. 267:1034-1041.

2. Jackson, S., et al. 1992. Combined enzyme defect of mitochondrial fatty acid oxidation. J. Clin. Invest. 90:1219-1225.

3. Kamijo, T., Aoyama, T., Komiyama, A., and Hashimoto, T. 1994. Structural analysis of cDNAs for subunits of human mitochondrial fatty acid $\beta$-oxidation trifunctional protein. Biochem. Biophys. Res. Commun. 199:818-825.

4. Sims, H.F., et al. 1995. The molecular basis of pediatric long chain 3hydroxyacyl-CoA dehydrogenase deficiency associated with maternal acute fatty liver of pregnancy. Proc. Natl. Acad. Sci. USA. 92:841-845.

5. Ushikubo, S., et al. 1996. Molecular characterization of mitochondrial trifunctional protein deficiency: formation of the enzyme complex is important for stabilization of both $\alpha$ - and $\beta$-subunits. Am. J. Hum. Genet. 58:979-988.

6. Ijlst, L., Ruiter, J.P.N., Hoovers, J.M.N., Jakobs, M.E., and Wanders, R.J.A. 1996. Common missense mutation G1528C in long-chain 3-hydroxyacyl-CoA dehydrogenase deficiency. Characterization and expression of the mutant protein, mutation analysis on genomic DNA and chromosomal localization of the mitochondrial trifunctional protein alpha subunit gene. J. Clin. Invest. 98:1028-1033.

7. Kamijo, T., et al. 1994. Mitochondrial trifunctional protein deficiency. Catalytic heterogeneity of the mutant enzyme in two patients. J. Clin. Invest. 93:1740-1747.

8. Hagenfeldt, L., Venizelos, N., and von Dobeln, U. 1995. Clinical and biochemical presentation of long chain 3-hydroxyacyl-CoA dehydrogenase deficiency. J. Inherit. Metab. Dis. 18:245-248.

9. Brackett, J.C., et al. 1995. Two $\alpha$-subunit donor splice site mutations cause human trifunctional protein deficiency. J. Clin. Invest. 95:2076-2082.

10. Ibdah, J.A., et al. 1998. Mild trifunctional protein deficiency is associated with progressive neuropathy and myopathy and suggests a novel genotype-phenotype correlation. J. Clin. Invest. 102:1193-1199.

11. Ibdah, J.A., et al. 1999. A fetal fatty-acid oxidation disorder as a cause of liver disease in pregnant women. N. Engl. J. Med. 340:1723-1731.

12. Wanders, R.J.A., et al. 1989. Sudden infant death and long-chain 3hydroxyacyl-CoA dehydrogenase. Lancet. 2:52-53.

13. Saudubray, J.M, et al. 1999. Recognition and management of fatty acid oxidation defects: a series of 107 patients. J. Inherit. Metab. Dis. 22:488-502.

14. Ibdah, J.A., Dasouki, M.J., and Strauss, A.W. 1999. Long-chain 3-hydroxyacyl-CoA dehydrogenase deficiency: variable expressivity of maternal illness during pregnancy and unusual presentation with infantile cholestasis and hypocalcaemia. J. Inherit. Metab. Dis. 22:811-814.

15. Wilcken, B., Leung, K.C., Hammond, J., Kamath, R., and Leonard, J.V. 1993. Pregnancy and fetal long-chain 3-hydroxyacyl coenzyme A dehydrogenase deficiency. Lancet. 341:407-408.

16. Tyni, T., Ekholm, E., and Pihko, H. 1998. Pregnancy complications are frequent in long-chain 3-hydroxyacyl-coenzyme A dehydrogenase deficiency. Am. J. Obstet. Gynecol. 178:603-608.

17. Ibdah, J.A., Yang, Z, and Bennett, M.J. 2000. Liver disease in pregnancy and fetal fatty acid oxidation defects. Mol. Genet. Metab. 71:182-189.

18. Chomczynski, P., and Sacchi, N. 1987. Single-step method of RNA isolation by acid guanidinium thiocyanate-phenol-chloroform extraction. Anal. Biochem. 162:156-159.

19. Laemmli, U.K. 1970. Cleavage of structural proteins during the assembly of the head of bacteriophage T4. Nature. 227:680-685.

20. Boles, R.G., Martin, S.K., Blitzer, M.G., and Rinaldo, P. 1994. Biochemical diagnosis of fatty acid oxidation disorders by metabolite analysis of postmortem liver. Hum. Pathol. 25:735-741.

21. Wanders, R.J.A., et al. 1992. Human trifunctional protein deficiency: a new disorder of mitochondrial fatty acid beta-oxidation. Biochem. Biophys. Res. Commun. 188:1139-1145.

22. Wanders, R.J.A., et al. 1999. Disorders of mitochondrial fatty acyl-CoA $\beta$-oxidation. J. Inherit. Metab. Dis. 22:442-487.

23. Bonnet, D., et al. 1999. Arrhythmias and conduction defects as presenting symptoms of fatty acid oxidation disorders in children. Circulation. 100:2248-2253.

24. Kurtz, D.M., et al. 1998. Targeted disruption of mouse long-chain acylCoA dehydrogenase gene reveals crucial roles for fatty acid oxidation. Proc. Natl. Acad. Sci. USA. 95:15592-15597. 